\title{
Frustration and sexual behavior in male rats
}

\author{
ESTEBAN FREIDIN and ALBA E. MUSTACA \\ Universidad de Buenos Aires, Buenos Aires, Argentina
}

\begin{abstract}
Frustration is an emotional state produced by the surprising omission in quantity and/or quality of an appetitive reinforcer. The aversive properties of stressors, such as electric shocks, produce responses similar to those elicited by a state of frustration. In this set of three experiments, we assessed the effects of water immersion (WIM, in Experiment 1) - that is, a physical stressor-and first (in Experiments 1 and 2) and second trials of a consummatory extinction (cE; i.e., a surprising reward omission; in Experiment 3) on the sexual behavior of male rats, as compared with nonstressed animals. The results showed a sexual deficit in the animals subjected to either WIM or cE, relative to control subjects, although these experimental conditions differed in the component of the male sexual response that was affected. The present results accord with the fear $=$ frustration hypothesis, and with Amsel's frustration theory.
\end{abstract}

The neuroendocrine response to stress is not limited to activation of the hypothalamo-pituitary-adrenal axis but also involves the hypothalamo-pituitary-gonadal system, among other neuroendocrine axes. Stress induced by physical or emotional challenges produces alterations in reproductive function. For example, males may exhibit suppression of testosterone secretion, spermatogenesis, and libido (Collu, Gibb, \& Ducharme, 1984; Rabin, Gold, Margioris, \& Chrousos, 1988). In addition, since the 1950s, the sexual behavior of rats has been shown to be vulnerable to a variety of stress situations. D'Aquila, Brain, and Willner (1994) showed that male rats reared in isolation and exposed to chronic mild unpredictable stress (i.e., unpredictable food, water deprivation, overnight illumination, $45^{\circ}$ cage tilt, periods of paired housing, periods in a soiled cage, and confinement in a smaller cage) exhibited decreased mounting in their sexual behavior. The effect of stress on sexual behavior depends on the nature, intensity, and in some conditions, duration of the stress stimulus. In a previous study (Retana-Márquez, Salazar, \& Velázquez-Moctezuma, 1996), the effects of many acute and chronic stress stimuli on the sexual behavior of male rats were compared. In its first occurrence, immersion of the animals in cold water $\left(15^{\circ} \mathrm{C}\right.$; i.e., an acute stressor $)$ increased their subsequent mount, intromission, and ejaculation latencies, relative to control subjects that were kept in their home cages. Restraint also increased intromission latencies, and electrical footshocks produced alterations in almost all sexual measures, but only when it was chronically applied. These stress-induced

This work was partly supported by UBACYT, Grants P602, N. 1022/03, and CONICET. The authors thank M. Bentosela, K. Hollis, R. Muzio, S. Pellegrini, E. Ruetti, three anonymous reviewers, and especially M. Papini, who made valuable comments on an earlier version of the manuscript. Correspondence concerning this article should be addressed to A. E. Mustaca or E. Freidin, IIM “A. Lanari”-Psicología Experimental y Aplicada, Combatientes de Malvinas 3150, (1426) Buenos Aires, Argentina (e-mail: mustaca@psi.uba.ar or efreidin@yahoo.com). sexual deficits are opposed to the stress-stimulatory effects on the copulatory activity of male rats shown in other studies. For example, tail pinch, tail shock, and flank shock stimulate and enhance sexual behavior in male rats (Caggiula, 1972; Caggiula \& Eibergen, 1969; Leyton \& Stewart, 1996).

Sexual alterations occur not only as a consequence of unconditioned physical stressors, but also in the presence of stimuli previously associated with them. It has been found that male rats placed in a context in which they had previously received electric shocks needed fewer numbers of mounts and intromissions to reach ejaculation than did animals that also received electric shocks but were assessed for sexual behavior in a neutral context (Beach \& Fowler, 1959). These results suggested that situational anxiety tended to reduce the amount or time of stimulation necessary to reach ejaculation in male rats. As can be seen from this brief overview, stress affects sexual behavior in a rather complex way: Stress can produce a deficit, an enhancement, or even no change in subsequent sexual performance. Chronic stress usually provokes sexual deficits, whereas acute mild stressors sometimes stimulate the copulatory activity of male rats. In summary, most stress-sexual-behavior studies have shown consequences of aversive physical stimuli and of aversive conditioned stimuli for copulatory responses, but the effects have not always been the same, varying according to the parameters used (i.e., nature, intensity, and/or duration of the stress stimulus).

It has been suggested that frustration (Amsel, 1958) or a surprising reward omission (SRO; Papini \& Dudley, 1997) — that is, the absence or reduction of an expected reinforcer in the presence of signals previously paired with the reward-has aversive effects and elicits negative emotional responses (Amsel, 1992; Papini \& Dudley, 1997). According to the frustration theory, an SRO induces an internal state, called primary frustration, which has both behavioral and physiological correlates, 
and is characterized by its unconditioned aversive and strengthening properties (i.e., induces increments in the vigor of subsequent responses). Different lines of evidence suggest such conclusions. (1) SROs promote the acquisition of responses that allow the animal to escape from the site where the omission has occurred (i.e., aversion). For example, rats learn to escape from a stimulus paired with the omission of an expected reward in a way similar to that by which they learn to escape from a key associated with electric shocks (Daly, 1974). (2) SROs trigger changes in agonistic behavior in social interactions (i.e., changes in subsequent behaviors). For example, pigeons display more aggressive behaviors toward another bird in the extinction phase of an appetitive conditioned keypecking response, rather than in the acquisition phase of that response (Azrin, Hutchinson, \& Hake, 1966). However, male rats show decreased agonistic behaviors after a consummatory successive negative contrast (cSNC; a successive downshift from a preferred to a less preferred reward; Mustaca \& Martínez, 2000) and after the extinction of a consummatory response (cE; Mustaca, Martínez, \& Papini, 2000). (3) SROs lead to the invigoration of subsequent responses (i.e., a frustration effect; Amsel \& Roussel, 1952). For example, using a doublerunway procedure in which two straight runways were connected in tandem, with the goal of the first serving as the start box of the second, Amsel and Roussel (1952) exposed rats to a partial reinforcement schedule in the first goal box and to a continuous reinforcement schedule in the second goal box. The key result involved a comparison of running speeds in the second runway as a function of whether the first goal box was reinforced (R) or nonreinforced $(\mathrm{N})$. Amsel and Roussel reported that rats ran faster after $\mathrm{N}$ trials than after $\mathrm{R}$ trials. (4) In a human infant analogue of contrast, a reduction in the number of elements in a mobile hanging over the cradle induced crying and gaze redirected away from the mobile (Fagen \& Rovee, 1976). (5) Plasma levels of the stress hormone corticosterone are elevated after a cSNC (Flaherty, Becker, \& Pohorecky, 1985) and after different extinction procedures (Davis, Memmott, MacFadden, \& Levine, 1976). (6) Drugs classified as anxiolytics in humans tend to reduce the behavioral effects of SROs (Gray, 1977, 1982; Mustaca, Bentosela, \& Papini, 2000).

These studies among others support the hypothesis that frustration has properties similar to those of fear (Amsel, 1958; Gray, 1982; Konorsky, 1964). For example, a review of over 400 studies in which many different species and anti-anxiety drugs were used showed that four kinds of inputs, including innate fear stimuli and signals of reward omission, produce behavioral inhibition, increased attention, and increased arousal (Gray, 1982). Interestingly, anti-anxiety drugs block these three behavioral outputs. Gray (1982) proposed that the brain systems mediating the response to threats of pain and threats of reward omission either are identical or, at least, overlap a great deal with each other and, thus, that frustration can be thought to be equivalent to fear.
The goal of the present experiments was to assess the potential effects of SROs on the sexual behavior of male rats, using a cE procedure (for a description, see Mustaca, Freidin, \& Papini, 2002). During the acquisition phase, one group of animals received two daily 5-min periods of access to a $32 \%$ sucrose solution, whereas the control group was not given access to the reinforcer. During the extinction phase, an empty sipper tube was presented to all the subjects. Goal-tracking time was used as the dependent measure in all the experiments. Previous studies have shown that goal-tracking time is positively correlated with reinforcer volume consumed by the animals (Mustaca et al., 2002; Mustaca \& Martelli, 2000). In those studies, it was also demonstrated that goaltracking time grows throughout the acquisition phase and decreases as a function of the extinction sessions, that spontaneous recovery occurs between nonreinforced trials (Mustaca et al., 2002), and that once the animals' responses are extinguished, a 1-min period of exposure to the sucrose solution produces a reinstatement effect on latency, although not on goal-tracking time (Freidin \& Mustaca, unpublished data).

In the present experiments, we tested many sexual performance measures of male rats after water immersion (WIM) and after first and second cE trials by placing a receptive female in the conditioning box. In Experiment 1, experimental subjects were exposed to two stressing situations (i.e., WIM, and cE, counterbalanced), after which they were sexually tested. In Experiment 2, the sexual behaviors of males that had previously gone through their first extinction trial were compared with those of never-reinforced control subjects, whereas in Experiment 3 , sexual performance was assessed after the second extinction trial.

\section{EXPERIMENT 1}

The goal of the present experiment was to evaluate the consequences of a physical stressor, WIM, and of a psychological stressor, $\mathrm{cE}$, for the subsequent sexual behavior of male rats. The copulatory performance of stressed rats was compared with that of nonstressed controls.

\section{Method}

Subjects. The subjects were 16 ejaculators selected out of 28 male Wistar rats (through a sexual pretest described in the Procedure section), all experimentally naive and bred at the Instituto de Investigaciones Médicas "Alfredo Lanari," Universidad de Buenos Aires. The rats were approximately 120 days old at the start of the experiment and weighed between 290 and $410 \mathrm{~g}$. They were housed in individual wire cages and were exposed to a 12:12-h light:dark cycle (light on from 06:00 to 18:00 h). Temperature was maintained at $23^{\circ} \mathrm{C}$. The animals had ad-lib access to water throughout the experiment. The rats were deprived of food until they reached $90 \%$ of their free-feeding weight; they were maintained at that level during the course of the experiment by daily access to food not less than 20 min after the end of the training session.

The 75-day-old female Wistar rats were housed in groups of 4-6 animals. They were ovariectomized 10 days before the beginning of the sexual pretests. 
Apparatus. The males' metallic home cages were $28 \mathrm{~cm}$ wide, $26 \mathrm{~cm}$ long, and $23 \mathrm{~cm}$ high, with bars $0.1 \mathrm{~cm}$ in diameter that were separated by $1.5 \mathrm{~cm}$. Consummatory training occurred in four conditioning boxes (MED Associates), each $29.2 \mathrm{~cm}$ long, $24.1 \mathrm{~cm}$ wide, and $21 \mathrm{~cm}$ high. The floor was made of aluminum bars measuring $0.4 \mathrm{~cm}$ in diameter and spaced $1.1 \mathrm{~cm}$ apart (from center to center). On one of the lateral walls, there was a cubicle measuring $5 \mathrm{~cm}$ in width, $5 \mathrm{~cm}$ in height, and $3.5 \mathrm{~cm}$ in depth and located $10 \mathrm{~cm}$ above the floor. The sipper tube was inserted into it from outside of the box, protruding approximately $2 \mathrm{~cm}$ inside the cubicle. The rat had to insert its head into this cubicle to reach the sipper tube, from which it could drink a $32 \%$ sucrose solution (32 g of sucrose for each $68 \mathrm{ml}$ of water). Goal-tracking time (in 0.01-sec units) was measured by a computer that registered the amount of time a photocell located in front of the drinking tube was activated during the trial. Each box was enclosed in a sound- and light-attenuating cubicle equipped with a source of white noise and a diffuse houselight. The conditioning boxes were also used for sexual behavior pretests and tests. These sexual experimental tests were recorded with two video cameras (Sharp VL-E685U and Sony Digital 8 DCR-TRV310 NTSC).

For the WIM procedure, a plastic tank, $50 \mathrm{~cm}$ in diameter and $100 \mathrm{~cm}$ high, was used. The water was at environmental temperature (approximately $21^{\circ} \mathrm{C}$ ) and reached $16 \mathrm{~cm}$ in depth; thus, the animals could remain in an upright position, keeping their heads above the water level.

Procedure. Table 1 shows a schematic representation of the design used in Experiment 1. The procedure had the following sequence.

Sexual pretest. The males were pretested for masculine sexual behavior; males displaying ejaculation at least once in a maximum of five 20-min sessions were selected. Conditioning boxes were used in sexual pretests to habituate the males to that context. Each male rat was placed in a conditioning box $30 \mathrm{sec}$ before the presentation of an ovariectomized receptive female. The female rats were brought into heat by administration of estradiol benzoate ( $50 \mu \mathrm{g} \mathrm{EB} / 0.1 \mathrm{ml}$ olive oil, $48 \mathrm{~h}$ before testing) and progesterone ( $500 \mu \mathrm{g} \mathrm{P} / 0.1 \mathrm{ml}$ olive oil, $2 \mathrm{~h}$ before testing). Before each sexual test, female receptivity was ensured by proving their lordosis (i.e., a female sexual response involving arched back and exposure of the genitals while the male is intending to mount) with sexually experienced, nonexperimental males. Pairs of male rats matched for ejaculation latency were randomly assigned to one of two groups:
Group E (exposed to WIM and $\mathrm{cE}, n=8$ ) and Group C (nonimmersed and never reinforced, $n=8$ ). The order of exposure to WIM and $\mathrm{cE}$ was counterbalanced.

On Day 0,2 days before the start of the consummatory training, all the experimental subjects received access to the training solution in their home cages. A drinking bottle with $40 \mathrm{ml}$ of solution was placed in the cage for $20 \mathrm{~min}$

WIM 1 and sexual test. On Day 1, a random half of the males in Group E were placed for $15 \mathrm{~min}$ in a plastic tank filled with water while the control subjects and the remaining half of the experimental subjects remained in their home cages. A towel was used to dry the rats immediately after they were taken out of the pool. The rats were returned to their home cages $45 \mathrm{~min}$ after the end of the WIM test; the rats were tested for sexual behavior in the conditioning boxes. At the same time, a random half of the control subjects were also tested. These parameters are like those used in similar experiments (see Retana-Márquez et al., 1996).

cE and sexual test. On Day 2, consummatory training began. From Day 2 to Day 7, the 16 subjects had a daily session in the conditioning boxes, each session consisting of two 5-min trials. The intertrial interval was about $2 \mathrm{~h}$, and the intersession interval was about $21 \mathrm{~h}$. The rats were placed in their home cages during both intervals. Squads of 4 rats were trained simultaneously, but the order of the squads and the conditioning box assigned to each animal were rotated across days. During each acquisition session, the subjects in Group E had access to $32 \%$ sucrose solution by licking the sipper tube. The sipper tube was empty for the control subjects. On Day 8, the sipper tube was empty for all the animals (i.e., the extinction phase). Immediately after the first extinction trial, a receptive female was placed into the conditioning box with the male, and sexual behavior was recorded for $20 \mathrm{~min}$.

WIM 2 and sexual test. From Day 9 to Day 14, the animals from both groups remained in their home cages in order to counterbalance the time between copulatory events. On Day 15, the other half of the experimental subjects went through the WIM procedure described before and then were sexually tested, together with the other half of the nonimmersed control subjects.

In short, the experimental subjects were sexually tested after WIM and also after cE, in a counterbalanced order, whereas the controls were kept out of both stressing conditions.

The following sexual performance measures were registered: mount latency (time from the introduction of the female to the oc-

Table 1

Schematic Representation of the Design Used in Experiment 1

\begin{tabular}{|c|c|c|c|c|c|c|c|}
\hline Group & $\begin{array}{c}\text { Sexual } \\
\text { Pretest } \\
\text { (Subject Selection) }\end{array}$ & $\begin{array}{c}\text { Day 0 } \\
\text { Preexposure }\end{array}$ & $\begin{array}{c}\text { Day } 1 \\
\text { WIM } 1 \text { and } \\
\text { Sexual Test }\end{array}$ & $\begin{array}{l}\text { Days 2-7 } \\
\text { Consummatory } \\
\text { Acquisition }\end{array}$ & $\begin{array}{c}\text { Day } 8 \\
\text { cE and } \\
\text { Sexual Test }\end{array}$ & Days 9-14 & $\begin{array}{l}\text { Day } 15 \\
\text { WIM } 2 \text { and } \\
\text { Sexual Test }\end{array}$ \\
\hline $\mathrm{E}$ & $\begin{array}{l}\text { Chance of } \\
\text { copulation }\end{array}$ & $\begin{array}{l}\text { Sugar in } \\
\text { home cage }\end{array}$ & $\begin{array}{l}\text { Half of the subjects: } \\
\text { WIM test, } \\
\text { followed by } \\
\text { the chance of } \\
\text { copulation }\end{array}$ & Sugar & $\begin{array}{l}\text { No sugar } \\
\text { followed by the } \\
\text { chance of } \\
\text { copulation }\end{array}$ & $\begin{array}{l}\text { Subjects were } \\
\text { kept in } \\
\text { their } \\
\text { home cages }\end{array}$ & $\begin{array}{l}\text { The other half of the } \\
\text { subjects: WIM test, } \\
\text { followed by the } \\
\text { chance of copulation }\end{array}$ \\
\hline $\mathrm{C}$ & Idem E & $\begin{array}{l}\text { No sugar } \\
\text { in home cage }\end{array}$ & $\begin{array}{l}\text { Half of the subjects: } \\
\text { no WIM test, } \\
\text { followed by } \\
\text { the chance of } \\
\text { copulation }\end{array}$ & No sugar & Idem E & Idem E & $\begin{array}{l}\text { The other half of the } \\
\text { subjects: no WIM test } \\
\text { followed by the } \\
\text { chance of copulation }\end{array}$ \\
\hline
\end{tabular}

Note-Experimental subjects (Group E) went through two stressing conditions in a counterbalanced order of exposure to water immersion (WIM) and consummatory extinction (cE). First, a random half of experimental subjects went through the WIM procedure and then were sexually tested, at the same time as the sexual test of a random half of the controls (i.e., Group C: not subjected to WIM). On the next day, all the experimentals began the consummatory training, and after 12 consummatory acquisition trials, they were shifted to cE and then were sexually tested, together with the never-reinforced subjects of Group C. The last part of the design consists of the WIM procedure and the respective sexual test for the other half of experimental and control subjects. Sugar: $32 \%$ sucrose solution. 
currence of the first mount), intromission latency (time from the introduction of the female to the first male penetration), mount frequency (number of mounts without intromission until ejaculation), intromission frequency (number of penetrations until ejaculation), ejaculation latency (time from the introduction of the female to ejaculation), copulation time (time from the first mount to ejaculation), copulatory efficiency (ratio between the number of intromissions and the total number of mounts), intermount interval (ratio between the copulation time and the total number of mounts), and postejaculatory interval (time from the first ejaculation to the next mount). An observer recorded these variables without knowing the animal's group assignment. Test-retest reliability was measured. The observer watched the same animal's sexual test twice. If there was $100 \%$ agreement between the two observations made by the same observer, confidence was achieved for that animal's test. If not, the same test was watched again, as many times as were needed to reach the criterion of a $100 \%$ matching between the data registered in two successive observations of it.

An analysis of variance (ANOVA) for the two independent groups $(\mathrm{E}$ and $\mathrm{C})$ and with trials as a repeated measure was conducted on goal-tracking time. Sexual behavior comparisons between groups were analyzed with the Mann-Whitney $U$ test. The alpha value was set at the .05 level. Two-tailed tests were used.

\section{Results and Discussion}

The main consummatory and extinction training results are presented in Figure 1. The average goal-tracking time increased throughout the acquisition trials for Group E but remained at a low constant level for Group C. These differences in consummatory behavior between groups were supported by a statistical analysis of the 12 acquisition trials, which showed significant effects of group $[F(1,14)=94.499, p<.001]$ and trial $[F(11,154)=$ $1.877, p<.04]$ and a significant group $\times$ trial interaction $[F(11,154)=3.222, p<.001]$.

A shift to extinction resulted in a sharp decline in Group E's goal-tracking time, reaching a level similar to that for Group C. An analysis of the last acquisition trial and the extinction performance together indicated significant effects of group $[F(1,14)=48.318, p<.001]$ and trial $[F(1,14)=23.446, p<.001]$ and a significant group $\times$ trial interaction $[F(1,14)=31.777, p<.001]$. No differences between groups were found in extinction scores $[F(1,14)=3.76]$.

The sexual performance of control and experimental groups after WIM is shown in Figure 2. No significant order effect of exposure to WIM, cE, and copulatory events was found in the sexual measures after $\mathrm{cE}$. Some components of the experimental subjects' sexual performance after WIM resulted in significant differences, relative to the controls' copulatory responses (see Figure 2). The experimental animals showed lower copulatory efficiency rates [averages, 0.36 vs. $0.52 ; U(8,8)=10, p<$ $.02]$, and marginally longer postejaculatory intervals [averages, $446 \mathrm{sec}$ vs. $373 \mathrm{sec} ; U(8,8)=14, p<.06]$. No statistical differences between groups were found in the remaining sexual variables after the immersion procedure.

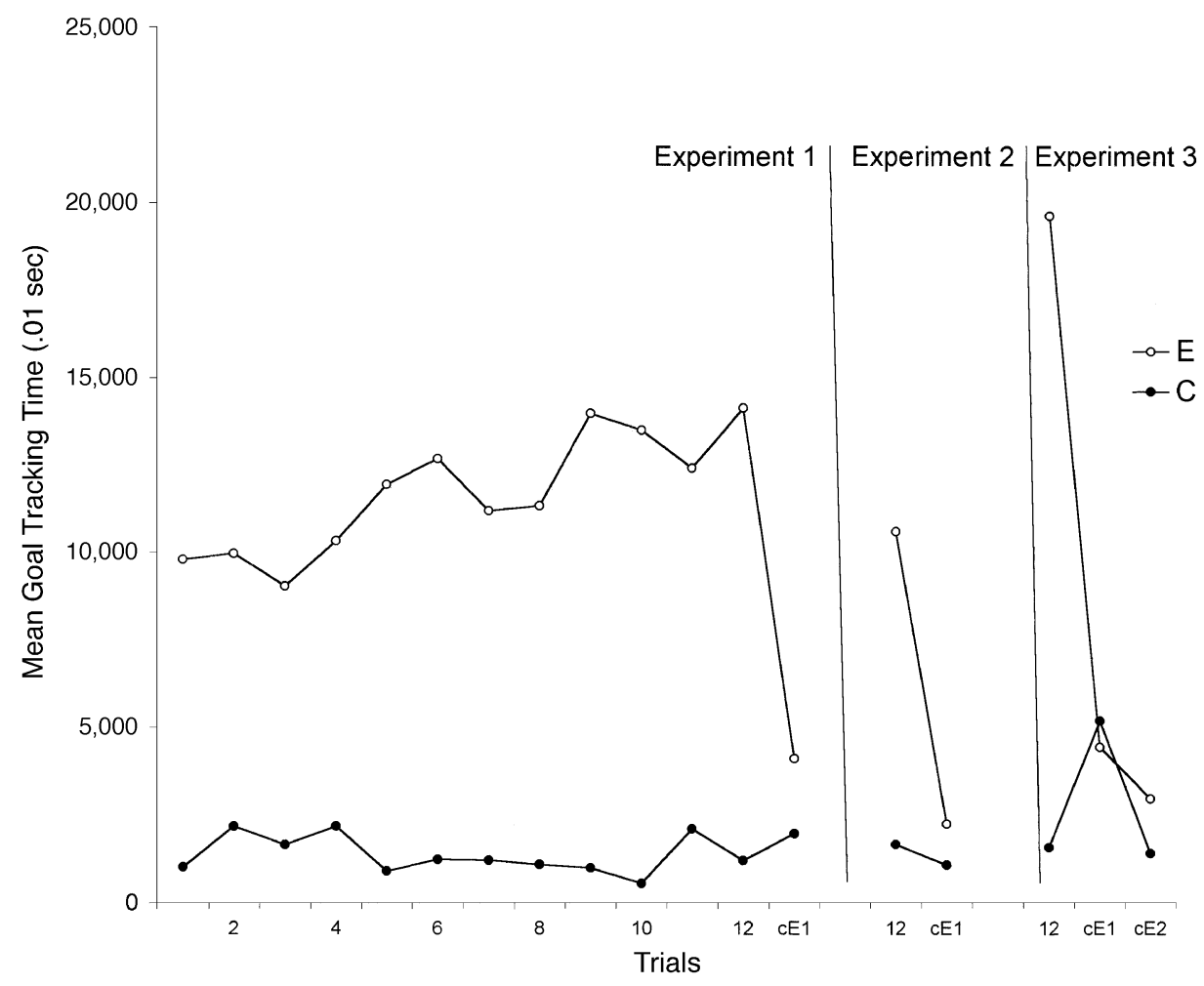

Figure 1. Consummatory performance, measured in terms of goal-tracking time as a function of reinforcer magnitude, trials, and experiments in $\mathbf{C E}$ procedures. $\mathrm{E}$, received $32 \%$ sucrose solution in acquisition trials and empty sipper tubes in extinction trials; $C$, never reinforced; cE, consummatory extinction. 

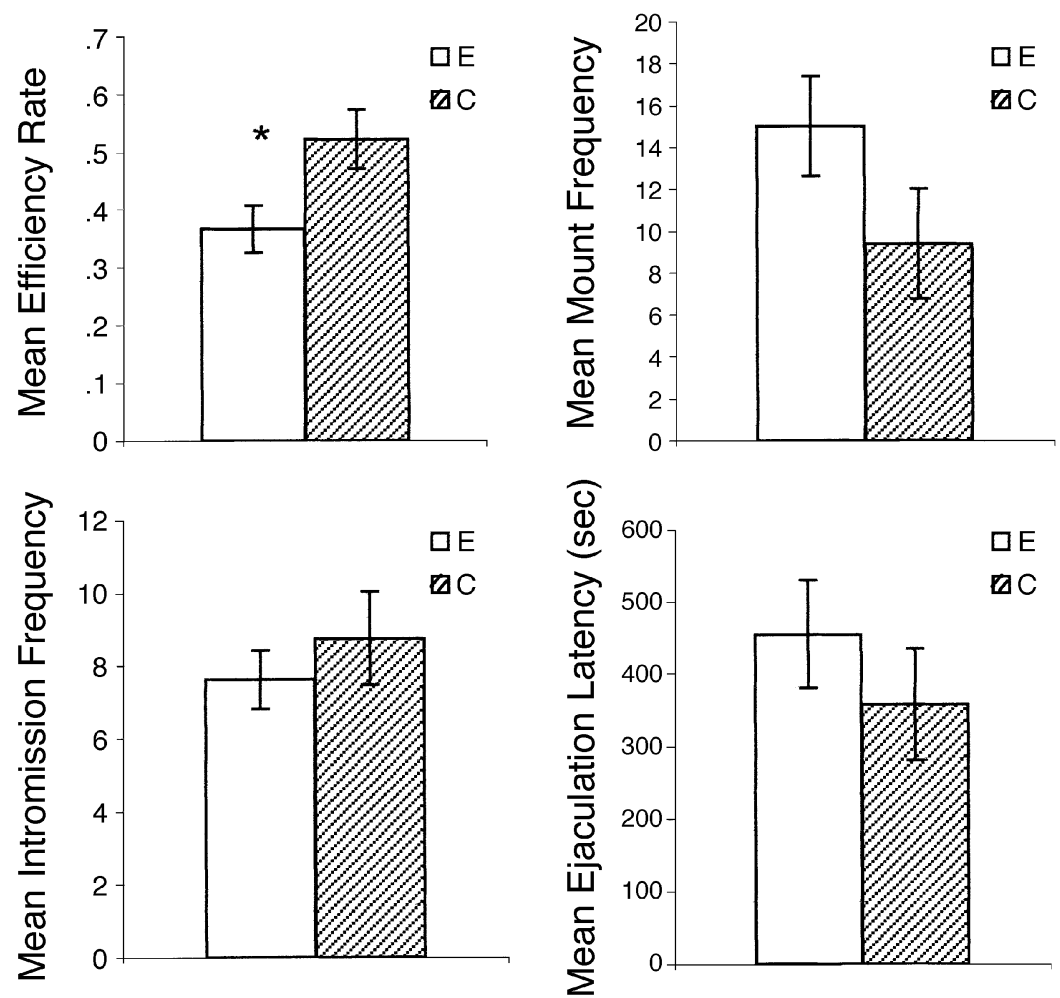

Figure 2. Sexual performance as a function of sexual test in the previous condition. E, after water immersion; C, not immersed. Error bars denote \pm 1 SEM. $\quad * p<.05$.

The sexual performance of the experimental subjects after $\mathrm{cE}$ was similar to that of the controls (all $p \mathrm{~s}>.05$ ).

The present experiment replicated the observation reported by Retana-Márquez et al. (1996) that rats exposed to WIM showed lower copulatory efficiency rates and a tendency to longer postejaculatory intervals, relative to nonstressed control subjects. Nevertheless, Retana-Márquez et al.'s (1996) WIM procedure had broader effects on sexuality (see the introduction), probably due to their use of colder water.

An SRO has been shown to induce emotional consequences similar to those elicited by aversive stimuli (Papini \& Dudley, 1997). However, the present experiment failed to show significant sexual response differences between the animals that experienced the SRO (i.e., cE) and the control subjects.

The present results seem to suggest that WIM may have been a more disruptive stressor for sexual behavior than was $\mathrm{cE}$. However, in this experiment, the sexual pretests, $\mathrm{cE}$ trials, and sexual tests were conducted in the same conditioning boxes, and thus, the context might have acquired appetitive associative value (Akins, 1998; Burns \& Domjan, 2001; Holloway \& Domjan, 1993). Such appetitive contextual conditioning could have interfered with the effects of frustration on sexual behavior. Although this procedure reduces context neophobia, it could also reduce frustration due to $\mathrm{cE}$ because of competition with a positive response conditioned during the sexual pretests.

\section{EXPERIMENT 2}

The main goal of this experiment was to assess the sexual behavior of male rats after a first $\mathrm{cE}$ trial, employing a procedure that eliminates possible contextual associations with copulatory opportunities. To achieve that goal, sexual pretests were administered in the subjects' homecages. No WIM procedure was included in this experiment.

\section{Method}

Subjects and Apparatus. The subjects were 23 ejaculators selected out of 50 male Wistar rats, all experimentally naive and bred at the Instituto de Investigaciones Médicas "Alfredo Lanari," Universidad de Buenos Aires. The rats were approximately 120 days old at the start of the experiment and weighed between 250 and $410 \mathrm{~g}$. They were housed in individual wire cages. The environmental and food deprivation conditions were exactly the same as those in Experiment 1 . The 120-day-old female Wistar rats were housed in groups of 4-6 animals. They were ovariectomized 15 days before the beginning of the sexual pretests.

Procedure. The procedure for selecting ejaculatory rats was similar to that in Experiment 1 . The only difference was that sexual pretests were run in each male's home cage. Then pairs of rats matched for ejaculation latency were randomly assigned to one of two groups: Group $\mathrm{E}$ (exposed to $\mathrm{cE}, n=11$ ) and Group C (never reinforced, $n=12$ ).

The $\mathrm{cE}$ and sexual test procedures were identical to those in $\mathrm{Ex}$ periment 1 . The animals were sexually tested immediately after the end of the last consummatory training trial.

Data were analyzed with the same statistical procedures as those described in Experiment 1. 


\section{Results and Discussion}

As in Experiment 1, the statistical analysis of goaltracking time on the 12 trials yielded significant effects of group $[F(1,21)=122.25, p<.001]$ and trial $[F(11,231)=$ 4.077, $p<.002]$ and a significant group $\times$ trial interaction $[F(11,231)=3.797, p<.003]$. The average goaltracking time increased throughout the trials in Group E, while remaining at low levels in Group C. In the cE trial, the goal-tracking time of the experimental subjects decreased sharply to almost the level of response for the control males. Last acquisition and cE trials analysis indicated significant effects of group $[F(1,21)=105.322$, $p<.001]$ and trial $[F(1,21)=111.488, p<.001]$ and a significant group $\times$ trial interaction $[F(1,21)=83.947$, $p<.001$; see Figure 1, Experiment 2]. Although Group E's average score almost matched that of the controls in the cE trial, the experimental animals' goal-tracking performance remained higher than that of the controls, and the analysis of that trial showed a significant effect of group $[F(1,21)=12.836, p<.02]$.

The sexual performance of the controls and of Group $E$ after the $\mathrm{cE}$ trial is shown in Figure 3. Experimental animals showed more mounts without intromission [averages, 11.36 vs. $5.58 ; U(11,12)=23.5, p<.02]$ and lower copulatory efficiency [averages, 0.49 vs. 0.64 ; $U(11,12)=27, p<.02]$, relative to controls. The other sexual components measured were not significantly different between groups.

The present results give evidence that a first $\mathrm{cE}$ trial had disruptive effects on subsequent sexual performance. The subjects that experienced the SRO (i.e., Group E) performed more mounts without intromission than did the control subjects, but the groups did not significantly differ in the number of intromissions; therefore, frustrated animals showed a lower copulatory efficiency. These results suggest that experimental animals might be more aroused (i.e., given their superior mount frequency) but less effective (i.e., given their lower efficiency rates) than controls. The sexual arousal conclusion could also be supported by the experimental animals' tendency to show shorter mount latencies and shorter intermount intervals, relative to those shown by the control males. This conclusion may be interpreted in terms of primary frustration (Amsel, 1958). Amsel, among other researchers, has shown that animals give evidence of a more intense response immediately after an SRO (see Papini \& Dudley, 1997).

Flaherty et al. (1985) and Flaherty, Greenwood, Martin, and Leszczuk (1998), however, found increased corticosterone levels after the 2 nd day of a cSNC procedure, but not after the animals had first detected the shift. They also observed that anxiolytic drugs reduced the behavioral
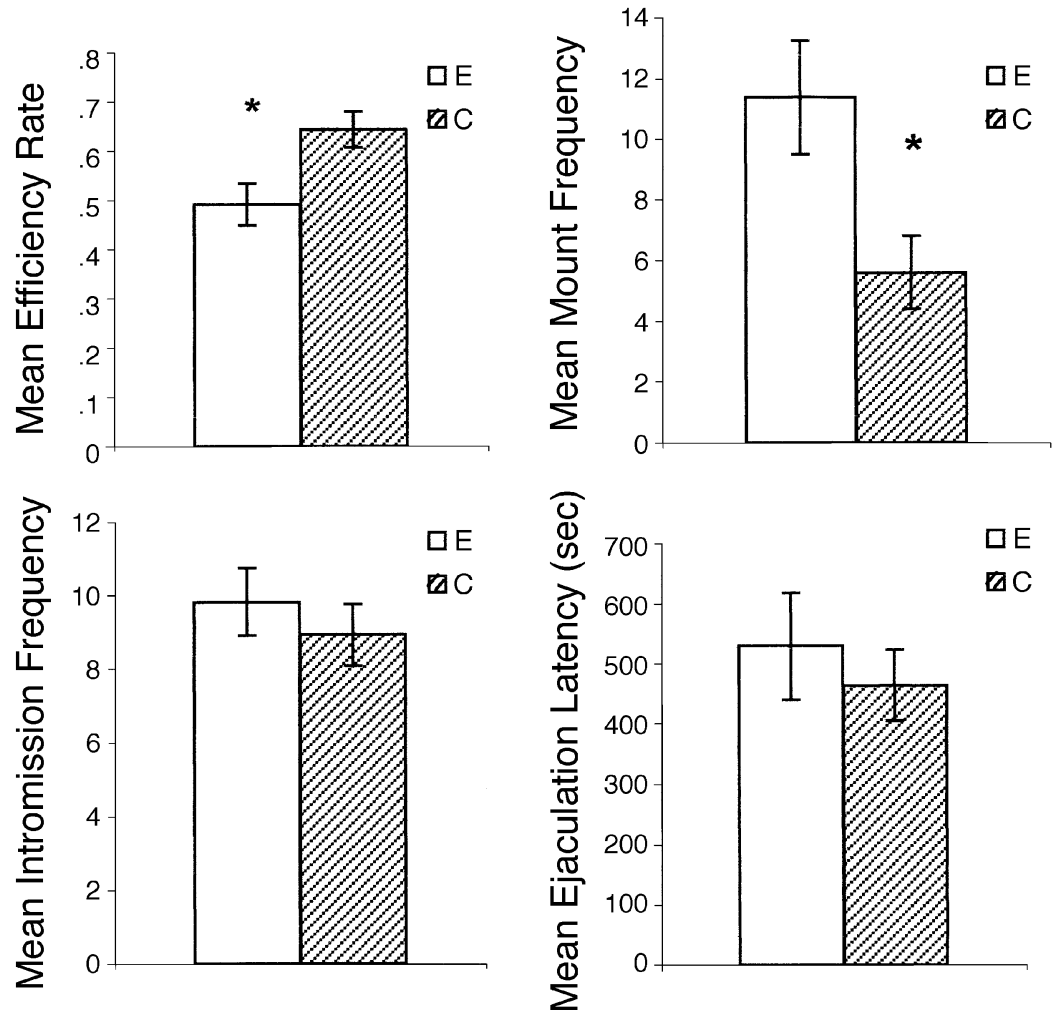

Figure 3. Sexual performance as a function of sexual test in the previous condition. $E$, after first trial of consummatory extinction; $C$, never reinforced. Error bars denote \pm 1 SEM. $\quad * p<.05$. 
contrast effect on the 2 nd, but not on the 1 st, day after the reinforcement downshift. On that basis, Flaherty proposed a multistage model for cSNC phenomena (Flaherty, 1996). He suggested that the emotional activation produced by a reinforcement reduction is preceded by a perceptual and cognitive stage, during which the animal detects the new situation, recalls the previous one, compares both, and develops exploratory behaviors searching for the missing reinforcer. After that cognitive evaluation, a second stage would be linked to frustrative emotional reactions in the subject that faced the SRO. Although this multistage model has reference to cSNC situations, $\mathrm{cE}$ is a similar procedure, and it can be interpreted as a maximization of the reward reduction, as compared with the typical cSNC procedure. If we consider that first and second encounters with reward omissions lead to different consequences, as Flaherty's multistage model predicts, we may expect a second trial of $\mathrm{cE}$ to have different effects on sexual behavior than those found after a first trial (i.e., more mounts without intromission and lower copulatory efficiency rates, relative to controls).

\section{EXPERIMENT 3}

The present experiment was designed to assess the consequences of a second trial of $\mathrm{cE}$ for the subsequent sexual behavior of male rats, employing the pretest procedure that eliminates possible associations of receptive females and copulatory opportunities (i.e., appetitive unconditioned stimuli) with the context (i.e., conditioned stimuli) in which the cE occurred next (i.e., the procedure used in Experiment 2).

\section{Method}

Subjects, Apparatus, and Procedure. The subjects were 14 ejaculators selected out of 32 male Wistar rats, all experimentally naive and bred at the Instituto de Investigaciones Médicas "Alfredo Lanari," Universidad de Buenos Aires. The rats were approximately 120 days old at the start of the experiment and weighed between 260 and $380 \mathrm{~g}$. The environmental and food deprivation conditions were the same as those in Experiments 1 and 2. The same female rats and apparatus as those in Experiment 1 were used. The selection of ejaculatory rats was conducted through pretests similar to those in Experiment 2. Then pairs of rats matched for ejaculation latency were randomly assigned to one of two groups: Group $\mathrm{E}(\mathrm{cE}$, $n=7$ ) and Group C (never reinforced, $n=7$ ).

The $\mathrm{cE}$ and sexual test procedures were identical to those in Experiment 2 , except that the experimental animals were sexually tested immediately after the end of the second extinction trial and the controls immediately after their respective nonreinforced trial. The same statistical criteria as those used to analyze the data in Experiments 1 and 2 were followed.

\section{Results and Discussion}

A rat from Group E was eliminated from the study because it failed to consume the reinforcer during three acquisition trials. All the other experimental animals consumed sucrose solution from the beginning of the experiment.

The main consummatory and extinction training results were very similar to those in Experiments 1 and 2 (see Figure 1, Experiment 3). The average goal-tracking time increased throughout the acquisition sessions for Group E, whereas Group C's average goal-tracking time remained at a low and almost constant level. The consummatory analysis of the 12 acquisition trials showed significant effects of group $[F(1,10)=213.181, p<$ $.001]$ and trial $[F(11,110)=5.011, p<.001]$ and a significant group $\times$ trial interaction $[F(11,110)=2.727$, $p<.004]$. Goal-tracking time of the experimental subjects sharply decreased during extinction and matched the control subjects' low scores, as also happened in the cE trials in Experiments 1 and 2. An ANOVA conducted on the data for the last acquisition and the two $\mathrm{cE}$ trials indicated significant effects of group $[F(1,10)=46.349$, $p<.001]$ and trial $[F(2,20)=54.406, p<.001]$ and a significant group $\times$ trial interaction $[F(2,20)=77.229$, $p<.001]$. No goal-tracking time differences between groups were found in the first $\mathrm{cE}$ session $[F(1,10)=$ $0.176]$; however, the experimental subjects showed a tendency to spend more time near the sipper tube in the second cE trial, relative to control animals $[F(1,10)=4.833$, $p<.05]$.

The sexual performance of the control and the experimental rats after the second trial of $\mathrm{cE}$ is shown in Figure 4. A rat from Group $C$ failed to reach ejaculation in the sexual test. Frequency of ejaculator and nonejaculator comparisons between groups were analyzed with a chisquare test, which resulted in a nonsignificant difference between groups $\left(\chi^{2}=1.077\right.$, n.s. $)$. Considering this chisquare analysis and that most sexual behavioral measures include or, at least, are related to the ejaculation response of the animal, only data from males that achieved ejaculation were used in the statistical analysis. Therefore, all the statistical analyses were conducted with the scores of 12 subjects (i.e., $n=6$, per group).

After the second trial of $\mathrm{cE}$, the experimental subjects showed evidence of disrupted sexual performance, relative to that of the control subjects. The results indicated that the experimental subjects exhibited significantly longer ejaculation latencies $(M=581.5 \mathrm{sec})$ than did the control animals $[M=316 \mathrm{sec} ; U(6,6)=5, p<.04]$. Group E also showed longer copulatory time (478 vs. $268 \mathrm{sec})$ and intermount interval (22 vs. $13 \mathrm{sec}$ ) averages than did Group C, although the statistical analysis showed that those sexual measures failed to reach significance $[U \mathrm{~s}(6,6) \leq 7, p<.1]$. Summing up, the experimental animals had longer ejaculation latencies after a second trial of $\mathrm{cE}$ than did the control subjects.

Like previous studies that have indicated that sexual performance changes after the occurrence of physical stressors, the present results give evidence that consummatory extinction also affects the subsequent sexual behavior of male rats when measured after first and second extinction trials. However, first and second cE trials' effects on subsequent sexual behavior were not the same, each one affecting different components of the experimental animals' sexual performance, as Flaherty's multistage model would predict. 

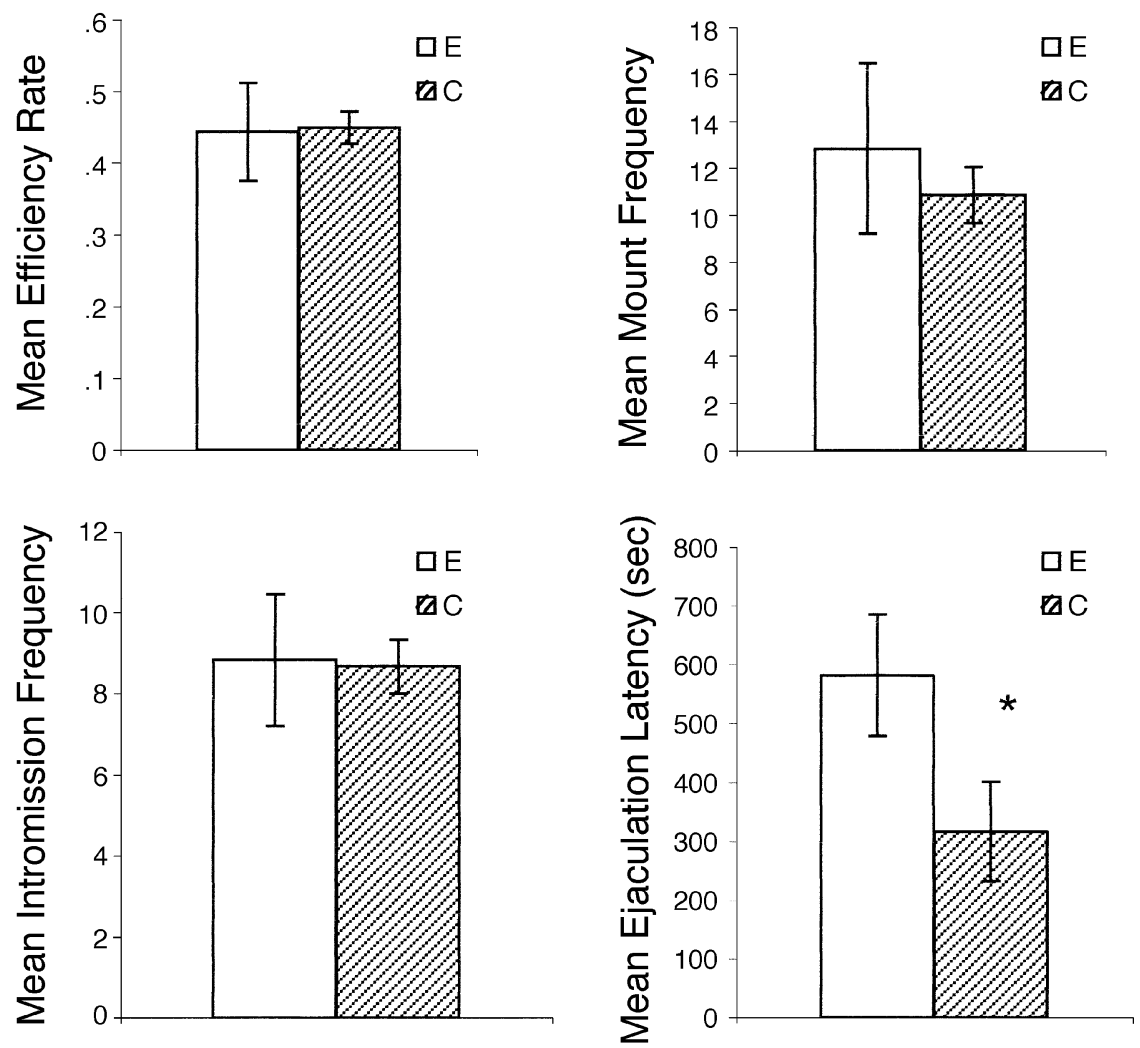

Figure 4. Sexual performance as a function of sexual test in the previous condition. E, after second trial of consummatory extinction; $C$, never reinforced. Error bars denote \pm 1 SEM. * $p<.05$.

\section{GENERAL DISCUSSION}

Previous studies showed that sexual behavior was affected after physical stressors (Retana-Márquez et al., 1996) and after stimuli associated to them (Beach \& Fowler, 1959) and that several experimental procedures involving SRO manipulations had stressing properties similar to those of unconditioned or conditioned aversive stimuli (for a review, see Papini \& Dudley, 1997). The experiments presented here provide the first evidence that the sexual behavior of male rats changes after the omission of an appetitive reinforcer (i.e., through a cE procedure) that is, after a psychological source of tension.

In Experiment 1, we replicated the observation that WIM used as a physical stressor harms sexual behavior in male rats, although we obtained weaker sexual changes after WIM than in a previous study (Retana-Márquez et al., 1996), probably due to our sexual pretest procedure (i.e., see the discussion in Experiment 1) and to the warmer water we used in our WIM tests. In Experiment 1, no sexual deficit was found after the first $\mathrm{cE}$ trial. The results of Experiment 2 suggest that Experiment 1's lack of sexual change after $\mathrm{cE}$ may have been related to the pretest procedure. Just changing the pretest cage (i.e., a home cage instead of the conditioning box; see the discussion in Experiment 1) led to an increase in mount fre- quency and a consequent impoverishment of copulatory efficiency in frustrated male rats in Experiment 2. In Experiment 3 , the results provided evidence that a psychological stressor such as frustration induced by a second trial of cE also impairs sexual performance in male rats. Nevertheless, a second trial of cE affected different components of the sexual response, relative to those altered after the first cE trial. The ejaculatory threshold (mainly reflected by ejaculation latency; Sachs \& Meisel, 1988) was modified by the second trial of $\mathrm{cE}$, but not by the first encounter with the reward omission. This same pattern of delayed ejaculation appeared in previous studies in which unconditioned aversive physical stimuli were used as stressors (Retana-Márquez et al., 1996). At the same time, the ejaculation performance obtained in the experimental subjects in Experiment 3 and in Retana-Márquez et al.'s (1996) subjects exposed to direct physical stimuli is opposite to the ejaculatio praecox observed when animals are sexually tested in a conditioned aversive context (Beach \& Fowler, 1959). These results suggest that unconditioned and conditioned aversive stimuli might have different effects on sexual responses.

In this set of experiments, we also obtained differential changes in sexual behavior after the first and second trials of $\mathrm{cE}$, which may suggest that the mechanisms involved in the first and second encounters with reward loss 
could be diverse. Amsel's frustration theory suggests that a reward loss triggers an internal aversive state with drive-energizing properties. On the one hand, Experiment 2's animals gave evidence of increased mount frequencies after the first $\mathrm{cE}$ exposure, a result analogous to a primary frustration effect (Amsel, 1992) - that is, the SRO's characteristic response-strengthening aftereffect. Another evidence of this invigorating effect of reward loss comes from a cSNC study in which rats that suffered a reinforcer downshift from a more preferred solution to a less preferred one exhibited significant increases in locomotor activity, relative to controls (Flaherty, Blitzer, \& Collier, 1978). On the other side, subjects that suffered from exposure to the second $\mathrm{cE}$ trial (as in Experiment 3) presented delayed ejaculation latencies, which could be partially explained by considering the experimental subjects' tendency toward longer intermount intervals. Since mounts and intromissions are intrinsically reinforcing, once begun, the behavior leading to them should be repeated with increasing frequency (see Ågmo, 1999). The experimental animals after the second $\mathrm{cE}$ trial took longer to mount again, relative to the control subjects' intermount intervals, probably evidencing a decrement in their sexual motivation (Sachs \& Meisel, 1988), which eventually led to longer ejaculation latencies.

In view of Experiment 3's finding that the second $\mathrm{cE}$ trial seemed to delay ejaculation in the same way as do unconditioned physical aversive stimuli, our results give support to the hypothesis that the mechanisms involved in the stress response triggered by aversive stimuli are similar to those triggered by the omission of appetitive reinforcers (Amsel, 1958; Gray, 1982, 1985; Konorsky, 1964). On the other hand, the animals' increased number of mounts after the first cE trial in Experiment 2 is consistent with Amsel's frustration theory, which predicts an invigorating effect after an SRO (see Amsel, 1992).

The alterations of reproductive behavior induced by SROs may involve the action of several hormones secreted during stressful situations, such as corticotrophin releasing factor (CRF; MacLusky, Naftolin, \& Leranth, 1988) and glucocorticoids, on hypothalamic-pituitarygonadal axis function (Doerr \& Pirke, 1976; Rivier, Rivier, $\&$ Vale, 1986). The infusion of CRF in the third ventricle of sexually experienced male rats suppresses sexual performance (Sirinathsinghji, 1987). However, plasma levels of testosterone were not modified by corticosterone administration (Retana-Márquez, Bonilla-Jaime, \& Velázquez-Moctezuma, 1998).

The present findings indicate that a procedure of $\mathrm{cE}$ impairs the subsequent sexual performance of male rats, thus extending the aftereffects of SROs to reproductive behavior. In addition, cE could now be used as a new procedure to assess stress mechanisms and the effects on sexual behavior of events that elicit "psychological pain."

\section{REFERENCES}

Ågmo, A. (1999). Sexual motivation: An inquiry into events determining the occurrence of sexual behavior. Behavioural Brain Research, 105, 129-150.
AKINS, C. K. (1998). Context excitation and modulation of conditioned sexual behavior. Animal Learning \& Behavior, 26, 416-426.

AMSEL, A. (1958). The role of frustrative nonreward in noncontinuous reward situations. Psychological Bulletin, 55, 102-119.

Amsel, A. (1992). Frustration theory: An analysis of dispositional learning and memory. New York: Cambridge University Press.

Amsel, A., \& Roussel, J. (1952). Motivational properties of frustration: Effect on a running response of the addition of frustration to the motivation complex. Journal of Experimental Psychology, 43, 363368.

Azrin, N. H., Hutchinson, R. R., \& HAKe, D. F. (1966). Extinction induced aggression. Journal of the Experimental Analysis of Behavior, 9, 191-204

BEACH, F., \& FowLER, H. (1959). Effects of situational anxiety on sexual behavior in male rats. Journal of Comparative \& Physiological Psychology, 52, 245-248.

BURNS, M., \& DOMJAN, M. (2001). Topography of spatially directed conditioned responding: Effects of context and trial duration. Journal of Experimental Psychology: Animal Behavior Processes, 27, 269-278.

CAGGIULA, A. R. (1972). Shock-elicited copulation and aggression in male rats. Journal of Comparative Physiology \& Psychology, 80, 393-397.

Caggiula, A. R., \& Eibergen, R. (1969). Copulation of virgin male rats evoked by painful peripheral stimulation. Journal of Comparative Physiology \& Psychology, 69, 414-419.

Collu, R., Gibb, W., \& Ducharme, J.-R. (1984). Effects of stress on the gonadal function. Journal of Endocrinological Investigation, 7 , 529-537.

DALY, H. B. (1974). Reinforcing properties of escape from frustration aroused in various learning situations. In G. H. Bower (Ed.), The psychology of learning and motivation (Vol. 8, pp. 187-232). New York: Academic Press.

D’Aquila, P. S., Brain, P., \& Willner, P. (1994). Effects of chronic mild stress on performance in behavioural tests relevant to anxiety and depression. Physiology \& Behavior, 56, 861-867.

Davis, H., Memmott, J., MacFadden, L., \& Levine, S. (1976). Pituitaryadrenal activity under different appetitive extinction procedures. Physiology \& Behavior, 17, 687-690.

DOERR, P., \& PIRKE, K. (1976). Cortisol-induced suppression of plasma testosterone in normal adult males. Journal of Clinical Endocrinological Metabolism, 43, 622-629.

FAGEN, J. W., \& RovEE, C. K. (1976). Effects of quantitative shifts in a visual reinforcer on the instrumental response of infants. Journal of Experimental Child Psychology, 21, 349-360.

FLAHERTY, C. F. (1996). Incentive relativity. New York: Cambridge University Press.

Flaherty, C. F., Becker, H. C., \& Pohorecky, L. (1985). Correlation of corticosterone elevation and negative contrast varies as a function of postshift day. Animal Learning \& Behavior, 13, 309-314.

Flaherty, C. F., Blitzer, R., \& Collier, G. H. (1978). Open-field behaviors elicited by reward reduction. American Journal of Psychology, 91, 429-443.

Flaherty, C. F., Greenwood, A., Martin, J., \& LeszczuK, M. (1998). Relationship of negative contrast to animal models of fear and anxiety. Animal Learning \& Behavior, 26, 397-407.

GRAY, J. A. (1977). Drug effects on fear and frustration: Possible limbic site of action of minor tranquilizers. In L. L. Iversen, S. D. Iversen, \& S. H. Snyder (Eds.), Handbook of psychopharmacology: Vol. 8. Drugs, neurotransmitters, and behavior (pp. 433-529). New York: Plenum.

GraY, J. A. (1982). The neuropsychology of anxiety: An enquiry into the function of the septo-hippocampal system. Oxford: Oxford University Press.

GraY, J. A. (1985). A whole and its parts: Behavior, the brain, cognition, and emotion. Bulletin of the British Psychological Society, 38, 99-112.

Holloway, K. S., \& Domjan, M. (1993). Sexual approach conditioning: Unconditioned stimulus factors. Journal of Experimental Psychology: Animal Behavior Processes, 19, 38-46.

KONORSKY, J. (1964). Integrative activity of the brain. Chicago: University of Chicago Press. 
Leyton, M., \& Stewart, J. (1996). Acute and repeated activation of male sexual behavior by tail pinch: Opioid and dopaminergic mechanisms. Physiology \& Behavior, 60, 77-85.

MacLuskY, N. J., NAFTOLin, F., \& LERANTH, C. (1988). Immunocytochemical evidence for direct synaptic connections between corticotrophin-releasing factor (CRF) and gonadotrophin-releasing hormone $(\mathrm{GnRH})$-containing neurons in the preoptic area of the rat. Brain Research, 439, 391-395.

Mustaca, A. E., Bentosela, M., \& Papini, M. R. (2000). Consummatory successive negative contrast in mice. Learning \& Motivation, 31, 272-282.

Mustaca, A. E., Freidin, E., \& Papini, M. R. (2002). Extinction of consummatory behavior in rats. International Journal of Comparative Psychology, 15, 1-10.

Mustaca, A. E., \& Martelli, M. I. (2000). Máxima discrepancia en el contraste consumatorio. VII Jornadas de Psicología, Universidad de Buenos Aires, Faculdad de Psicología.

Mustaca, A. E., \& Martínez, C. (2000). Respuestas agonísticas en ratas sometidas a frustración. Revista Latinoamericana de Psicología, 32, 485-504.

Mustaca, A. E., Martínez, C., \& Papini, M. R. (2000). Surprising nonreward reduces aggressive behavior in rats. International Journal of Comparative Psychology, 13, 91-100.

PAPINI, M. R., \& Dudley, R.T. (1997). Consequences of surprising reward omissions. Review of General Psychology, 3, 275-285.
Rabin, D., Gold, P. W., Margioris, A. N., \& Chrousos, G. P. (1988). Stress and reproduction: Physiologic and pathophysiologic interactions between the stress and reproductive axes. In G. P. Chrousos, D. L. Loriaux, \& P. W. Gold (Eds.), Mechanisims of physical and emotional stress (Advances in Experimental Medical Biology, Vol. 245, pp. 377-387). New York: Plenum.

Retana-Márquez, S., Bonilla-Jaime, H., \& Velázquez-Moctezuma, J. (1998). Lack of effect of corticosterone administration on male sexual behavior of rats. Physiology \& Behavior, 63, 367-370.

Retana-Márquez, S., Salazar, E. D., \& Velázquez-Moctezuma, J. (1996). Effect of acute and chronic stress on masculine sexual behavior in the rat. Psychoneuroendocrinology, 21, 39-50.

Rivier, C., Rivier, J., \& VALE, W. (1986). Stress-induced inhibition of reproductive functions: Role of endogenous corticotropin-releasing factor. Science, 231, 607-609.

Sachs, B. D., \& MEISEL, R. L. (1988). The physiology of male sexual behavior. In E. Knobil \& J. D. Neill (Eds.), The physiology of reproduction (pp. 1393-1486). New York: Raven.

SiRINATHSINGHJI, D. J. S. (1987). Inhibitory influence of corticotrophin releasing factor on components of sexual behavior in the male rat. Brain Research, 407, 185-190.

(Manuscript received May 12, 2003; revision accepted for publication November 10, 2003.) 